\title{
Oxidative stress biomarkers in pulmonary tuberculosis patients in Gombe, North-eastern Nigeria
}

\author{
Mohammed Haruna Yeldu', Yakubu Ibrahim², Shehu Abubakar Akuyam³, \\ Isah Muhammad Danasabe ${ }^{4}$, Buhari Shehu ${ }^{5}$, Mohammed Danjuma ${ }^{6}$, Miftahu Bello \\ Usman Yahaya $^{8}$ \\ ${ }^{1}$ Associate Professor, ${ }^{5}$ Lecturer I, School of Medical Laboratory Sciences, Usmanu Danfodiyo University Sokoto, \\ Nigeria, ${ }^{2,8}$ Lecturer II, ${ }^{3}$ Professor, Department of Medical Laboratory Science, Ahmadu Bello University Zaria, \\ ${ }^{4}$ Consultant Physician and Senior Lecturer, Department of Internal Medicine, Usmanu Danfodiyo University Teaching \\ Hospital, Sokoto, Nigeria, ${ }^{6}$ Chief Medical Laboratory Scientist, Federal Medical Centre, Birnin Kebbi, Nigeria, ${ }^{7}$ Senior \\ Medical Laboratory Scientist, State Specialist Hospital, Sokoto, Nigeria
}

Background: Oxidative stress may play an important role in the pathogenesis of pulmonary tuberculosis (PTB). To our knowledge there is paucity of data on the status of oxidative stress biomarkers among PTB patients in Gombe, North-eastern Nigeria. Our study was designed to evaluate the oxidative stress biomarkers in pulmonary tuberculosis patients in Gombe, North-eastern Nigeria. Aims and Objectives: To determine the serum levels of oxidative stress biomarkers among patients with pulmonary tuberculosis in Gombe metropolis, North-eastern Nigeria and to assess the correlation between the oxidative stress biomarkers in pulmonary tuberculosis patients. Materials and Methods: A cross sectional comparative study was conducted in a tertiary health care facility with 40 pulmonary tuberculosis (PTB) patients on anti-TB drugs treatment (ATT), 40 newly diagnosed PTB patients not yet on anti-TB drugs treatment (ATT-naïve) and 40 age- and sex-marched apparently healthy subjects (controls). Serum total antioxidant status (TAS), total oxidant status (TOS), malondialdehyde (MDA), nitric oxide (NO) and oxidative stress index (OSI) were determined using standard techniques. Data was analysed using InStat ${ }^{\circledR}$ (GraphPad Software Inc., La Jolla, CA, USA). Results: Serum levels of TOS, OSI, MDA and NO were significantly $(p<0.001)$ increased in PTB patients (ATT and ATT-naïve) when compared with healthy individuals. Serum TAS and body mass index (BMI) were significantly $(\mathrm{p}<0.001)$ decreased in PTB patients when compared with healthy individuals. Serum TOS significantly correlated with serum OSI, MDA and NO in ATT-naïve PTB patients. Conclusion: This study observed an increased oxidative stress biomarkers and decreased total antioxidant status in newly diagnosed pulmonary tuberculosis patients and those on treatment. Our findings suggest that antioxidants supplementation and improved nutrition in the management of pulmonary tuberculosis patients may go a long way in preventing the oxidative onslaught and further complications in PTB patients.

Key words: Pulmonary tuberculosis; oxidative stress; Gombe-Nigeria
Access this article online Website: http://nepjol.info/index.php/AJMS DOI: 10.3126/ajms.v10i6.25593 E-ISSN: 2091-0576 P-ISSN: 2467-9100

\section{INTRODUCTION}

Pulmonary tuberculosis (PTB) resulting from infection by Mycobacterium tuberculosis remains to be the leading cause of morbidity and mortality worldwide. It causes significant health challenges to developing economies as it affects people during their most productive years. It is a second major cause of morbidity and mortality in the developing countries after human immunodeficiency virus (HIV) with the latest estimated cases of 9 million in 2011 and 1.4 million tuberculosis deaths (990,000 among HIV-negative people and 430,000 HIV-associated TB deaths). ${ }^{1}$ 
Oxidative stress (OS) due to an imbalance between reactive oxygen species (ROS) and antioxidant defence mechanism in favour of the former has been implicated in the pathogenesis of many diseases including PTB. ${ }^{2-4}$ This ratio can be altered by increased generation of reactive oxygen species (ROS) and/or reactive nitrogen species (RNS), or a decrease in antioxidant defense mechanisms. ${ }^{5}$ Oxidative stress induces alterations in the cell membranes and other structures such as proteins, lipids, lipoproteins and deoxyribonucleic acid. ${ }^{6}$

Infection by Mycobacterium tuberculosis has been proved to induce oxidative stress by promoting increase ROS generation by both mononuclear and polymorphonuclear phagocytes. The M. tuberculosis is therefore capable of initiating and facilitating oxidative damage to biomolecules and cellular structures such as DNA, proteins and lipids. ${ }^{7}$

Weaken antioxidant status have earlier been reported in PTB patients which might render the host to the oxidative tissue damage. PTB is also associated with derangement in oxidant-antioxidant balance which is essential for the normal lung function. An increase in oxidants with decrease in antioxidant defense might lead to development of lung dysfunction causing tissue injury. ${ }^{8}$

To the best our knowledge, there is paucity of data on the status of oxidative stress biomarkers among PTB patients in Gombe, North-eastern Nigeria. The objective of this study is to assess the oxidative stress biomarkers in pulmonary tuberculosis patients in Gombe, North-eastern Nigeria.

\section{MATERIALS AND METHODS}

The study was across sectional comparative study that included 40 newly diagnosed pulmonary tuberculosis (PTB) patients not yet on anti-TB drugs treatment (AT'T-naïve) and 40 PTB patients on anti-TB drugs treatment (ATT) attending Tuberculosis and Leprosy (TBL) Treatment Centre of State Specialist Hospital, Gombe North-eastern Nigeria, and 40 age- and sex-marched apparently healthy controls. The study protocol was approved by the Ethics and Research Committee of Gombe State Ministry of Health. All the study subjects were counselled and were informed about the study and informed consent was obtained from each subject prior to the commencement of the study. The study was conducted from June, 2018 to November, 2018.

With the aid of a structured interviewer administered questionnaire, socio-demographic characteristics including age, gender, marital status, tribe, occupation and educational levels of the study subjects were obtained. Confirmed PTB patients who were non-smokers between the age of 18 to
60 years and were newly diagnosed and yet to commence TB treatment (AT"T-naïve) and those on ATT as well as apparently healthy adults were included in the study. The PTB patients with previous history of HIV-infection, diabetes mellitus, hepatitis $\mathrm{B}$ and $\mathrm{C}$ positive, pregnant women, above 60 or below 18 years of age, and those patients with any history of chronic disease were excluded.

The heights of the subjects were measured using a calibrated Stadiometer, model 220 (manufactured by Seca Gmbh and Co., Germany). The subjects were weighed with minimum clothing to the nearest $0.1 \mathrm{~kg}$ using a regularly calibrated health weighing scale; model ZT 120 (manufactured by Seca Gmbh and Co., Germany). Body mass index (BMI) was calculated using the expression: BMI $\left(\mathrm{kg} / \mathrm{m}^{2}\right)=$ Body weight $(\mathrm{kg}) /$ Height $\left(\mathrm{m}^{2}\right)$.

From each subject, about $5 \mathrm{ml}$ of venous blood sample was collected into plain Vacutainer blood sample bottle (Becton Dickson) and allowed to clot and later centrifuged at $5000 \mathrm{rpm}$ for 10 minutes and the clear unhaemolyzed sera harvested into two aliquots in sterile cryovials (Delta Lab, Barcelona, Spain). Serum total antioxidant status (TAS) and total oxidant status (TOS) were measured by the method of Benzie and Strain. ${ }^{9}$ oxidative stress index (OSI) was calculated as: OSI (arbitrary unit) $=[($ TOS $(\mu \mathrm{mol} / \mathrm{l}) /$ (TAS $(\mu \mathrm{mol} / \mathrm{l})]$ multiplied by 100 , malondialdehyde (MDA) by Shah and Walker method ${ }^{10}$ and nitric oxide (NO) was measured according to Norwad method. ${ }^{11}$

\section{Statistical analysis}

Data generated was analysed using InStat ${ }^{\circledR}$ (GraphPad Software Inc., La Jolla, CA, USA). Result was expressed as mean \pm SEM. Paired comparison was made using independent sample t-test, one way analysis of variance (ANOVA) was used to compare three or more mean values followed by Bonferroni's multiple comparison test. Correlation between biomarkers of oxidative stress was carried out using Pearson's linear correlation analysis. $P$ value of less than or equal to $0.05(\mathrm{p} \leq 0.05)$ was regarded as statistically significant.

\section{RESULTS}

In the present study, the socio-demographic characteristics of the study subjects (Table 1) indicated that most of the subjects including the controls $(15 ; 37.5 \%)$, PTB ATTnaïve $(15 ; 15 \%)$ and PTB on ATT $(17 ; 42.5 \%)$ belong to age range of 29-39 years. Gender distribution among the study subjects were $26(65 \%), 22(55 \%)$ and $32(80 \%)$ for males among the controls, PTB ATT-naïve and PTB on ATT respectively while females were $14(35 \%), 18(45 \%)$ and $8(20 \%)$ among the controls, PTB AT'T-naïve and PTB on ATT respectively. 


\begin{tabular}{|c|c|c|c|}
\hline $\begin{array}{l}\text { Characteristics } \\
\mathrm{N}\end{array}$ & $\begin{array}{l}\text { Control } \\
40(\%)\end{array}$ & $\begin{array}{c}\text { PTB } \\
\text { ATT-naïve } \\
40(\%)\end{array}$ & $\begin{array}{c}\text { PTB on } \\
\text { ATT } \\
40(\%)\end{array}$ \\
\hline \multicolumn{4}{|l|}{ Age range } \\
\hline $18-28$ & $8(20)$ & $14(35)$ & $7(17.5)$ \\
\hline $29-39$ & $15(37.5)$ & $10(25)$ & $17(42.5)$ \\
\hline $40-50$ & $8(20)$ & $7(17.5)$ & $10(25)$ \\
\hline $51-61$ & $9(22.5)$ & $9(22.5)$ & $6(15)$ \\
\hline \multicolumn{4}{|l|}{ Gender } \\
\hline Male & $26(65)$ & $22(55)$ & $32(80)$ \\
\hline Female & $14(35)$ & $18(45)$ & $8(20)$ \\
\hline \multicolumn{4}{|l|}{ Tribe } \\
\hline Hausa & $16(40)$ & $10(25)$ & $13(32.5)$ \\
\hline Fulani & $9(22.5)$ & $17(42.5)$ & $14(35)$ \\
\hline Yoruba & $2(5)$ & $1(2.5)$ & $0(0)$ \\
\hline Igbo & $2(5)$ & $1(2.5)$ & $0(0)$ \\
\hline Others & $11(27.5)$ & $11(27.5)$ & $13(32.5)$ \\
\hline \multicolumn{4}{|l|}{ Marital status } \\
\hline Single & $8(20)$ & $10(25)$ & $10(25)$ \\
\hline Married & $20(50)$ & $17(42.5)$ & $25(62.5)$ \\
\hline Divorced & $7(17.5)$ & $3(7.5)$ & $3(7.5)$ \\
\hline Widowed & $5(12.5)$ & $10(25)$ & $2(5)$ \\
\hline \multicolumn{4}{|c|}{ Educational background } \\
\hline Primary & $2(5)$ & $8(20)$ & $6(15)$ \\
\hline Secondary & $14(35)$ & 9 (22.5) & $17(42.5)$ \\
\hline Tertiary & $18(45)$ & $6(15)$ & $4(10)$ \\
\hline Arabic only & $6(15)$ & $14(35)$ & $13(32.5)$ \\
\hline Non formal & $0(0)$ & $3(7.5)$ & $0(0)$ \\
\hline \multicolumn{4}{|l|}{ Occupation } \\
\hline Civil Servant & $24(60)$ & $4(10)$ & $5(12.5)$ \\
\hline House Wife & $5(12.5)$ & $9(22.5)$ & $4(10)$ \\
\hline Business & $3(7.5)$ & $4(10)$ & $14(35)$ \\
\hline Handwork & $5(12.5)$ & $3(7.5)$ & $5(12.5)$ \\
\hline Others & $3(7.5)$ & $20(50)$ & $12(30)$ \\
\hline \multicolumn{4}{|l|}{ Type of family } \\
\hline Monogamous & $26(65)$ & $17(42.5)$ & $25(62.5)$ \\
\hline Polygamous & $14(35)$ & $23(57.5)$ & 15 (37.5) \\
\hline \multicolumn{4}{|l|}{ Treatment status } \\
\hline Yes & $0(0)$ & $0(0)$ & $40(100)$ \\
\hline No & $40(100)$ & $40(100)$ & $0(0)$ \\
\hline \multicolumn{4}{|c|}{ Treatment duration } \\
\hline $1-2$ months & $0(0)$ & $0(0)$ & $10(25)$ \\
\hline 3-4 months & $0(0)$ & $0(0)$ & $12(30)$ \\
\hline $5-6$ months & $0(0)$ & $0(0)$ & 15 (37.5) \\
\hline$>6$ months & $0(0)$ & $0(0)$ & $3(7.5)$ \\
\hline Not on drugs & $40(100)$ & $40(100)$ & $0(0)$ \\
\hline
\end{tabular}

Fulani tribe had the highest number of individuals infected with $M$. tuberculosis with 17 (42.5\%) and 14 (35\%) for PTB patients AT'T-naïve and PTB patients on ATT respectively), followed by Hausa with 10 (25\%) and $13(32.5 \%)$ respectively among the $M$. tuberculosis infected groups. Regarding the other tribes, PTB AT'T-naïve and PTB on ATT had 11 (27.5\%) and 13 (32.5\%) respectively. The least number of individuals were among the Yoruba and Igbo with $1(2.5 \%)$ and $0(0 \%)$ among PTB AT'Tnaïve and PTB on AT'T respectively. Level of education of the study participants showed that; those with Arabic

\begin{tabular}{|c|c|}
\hline \multicolumn{2}{|l|}{$\begin{array}{l}\text { Table } 2: \mathrm{Cc} \\
\text { of patients } \\
\text { controls }\end{array}$} \\
\hline Group & BMI $\left(\mathrm{kg} / \mathrm{m}^{2}\right)$ \\
\hline Controls & $23.48 \pm 1.71$ \\
\hline PTB ATT-naïve & $14.95 \pm 3.51^{b}$ \\
\hline PTB on ATT & $16.80 \pm 2.17^{a, b}$ \\
\hline \multicolumn{2}{|c|}{$\begin{array}{l}\text { Data expressed as mean } \pm \text { SEM; } n=\text { number of subjects; PTB ATT-naïve=pulmonary } \\
\text { tuberculosis and anti-tuberculous therapy-naïve; PTB on ATT=pulmonary } \\
\text { tuberculosis on anti-tuberculous therapy drugs; values differ significantly at }{ }^{a} p<0.01 ; \\
{ }^{b} p<0.001 \text { by Bonferroni's multiple comparison test. }\end{array}$} \\
\hline
\end{tabular}

education had the highest number of cases with 14 (35\%) and 13 (32.5\%) among PTB ATT-naïve and PTB on ATT respectively. Patients with secondary school education were $9(22.5 \%)$ and 17 (42.5\%) among PTB ATT-naïve and those on ATT respectively. Participants with tertiary and non-formal education were $6(15 \%)$ and $4(10 \%)$ among PTB ATT-naïve and those on ATT respectively.

The mean body mass index (BMI) in PTB ATT-naïve and PTB on ATT decreased significantly $(\mathrm{P}<0.01 ; \mathrm{p}<0.001$ respectively) compared to controls (Table 2). Mean serum TAS in PTB ATT-naïve and PTB on ATT decreased significantly $(\mathrm{P}<0.01 ; \mathrm{p}<0.001$ respectively) compared to controls while serum TOS and OSI levels increased significantly $(\mathrm{P}<0.001)$ compared to similar values in controls. In comparison between the two groups of PTB patients, serum TOS levels in PTB ATT-naïve increased significantly ( $\mathrm{P}<0.01)$ compared to PTB patients on ATT (Table 3).

The serum nitric oxide (NO) and malondialdehyde (MDA) of patients with pulmonary tuberculosis and controls (Table 4) indicated significantly $(\mathrm{P}<0.001)$ increased serum MDA and NO in both PTB ATT-naïve and PTB patients on ATT compared to controls. The serum MDA levels were significantly $(\mathrm{p}<0.001)$ increased in PTB ATT-naïve as compared with PTB patients on ATT (Table 4).

With the exception of serum TAS which did not correlate with OSI $(r=-0.138, P=0.396)$, serum MDA and NO levels were positively correlated with OSI $(\mathrm{r}=0.367$, $\mathrm{P}=0.020 ; \mathrm{r}=0.642, \mathrm{p}=0.000$ respectively) in PTB ATTnaïve patients (Table 5).

On the other hand, serum TOS levels were positively correlated with serum OSI $(r=0.991, \mathrm{P}=0.000$; Figure 1A) and showed the same relationship with oxidative stress measured by MDA levels $(r=0.385, P=0.014$; Figure 1B) and serum NO levels $(\mathrm{r}=0.644, \mathrm{P}=0.000$; Figure $1 \mathrm{C})$ in anti-tuberculosis therapy naïve PTB patients. 
Table 3: Serum levels of total antioxidant status (TAS), total oxidant status (TOS) and oxidative stress index (OSI) of patients with pulmonary tuberculosis and controls

\begin{tabular}{lcccc}
\hline Group & N & TAS $(\mu \mathrm{mol} / \mathrm{l})$ & TOS $(\mu \mathrm{mol} / \mathrm{l})$ & OSI \\
\hline Controls & 40 & $1224.00 \pm 14.65$ & $4.32 \pm 0.48$ & $0.35 \pm 0.04$ \\
PTB ATT-naïve & 40 & $783.42 \pm 9.17^{\mathrm{a}}$ & $15.78 \pm 1.46^{\mathrm{b}}$ & $2.02 \pm 0.19^{\mathrm{b}}$ \\
PTB on ATT & 40 & $768.00 \pm 11.98^{\mathrm{b}}$ & $13.80 \pm 2.56^{\mathrm{a}, \mathrm{b}}$ & $1.85 \pm 0.33^{\mathrm{b}}$ \\
\hline
\end{tabular}

Data expressed as mean \pm SEM; $n=$ number of subjects; PTB ATT-naïve=pulmonary tuberculosis and anti-tuberculous therapy-naïve; PTB on ATT=pulmonary tuberculosis on anti-tuberculous therapy drugs; values differ significantly at ${ }^{\mathrm{a}} \mathrm{p}<0.01 ;{ }^{\mathrm{b}} \mathrm{p}<0.001$ by Bonferroni's multiple comparison test.

\begin{tabular}{|c|c|c|c|}
\hline Group & $\mathbf{N}$ & MDA (nmol/ml) & $\mathrm{NO}(\mu \mathrm{mol} / \mathrm{l})$ \\
\hline Controls & 40 & $1.72 \pm 0.11$ & $2.53 \pm 0.30$ \\
\hline PTB ATT-naïve & 40 & $4.11 \pm 0.22^{b}$ & $3.75 \pm 2.78^{b}$ \\
\hline PTB on ATT & 40 & $2.56 \pm 0.15^{\mathrm{a}, \mathrm{b}}$ & $2.93 \pm 0.24^{b}$ \\
\hline \multicolumn{4}{|c|}{$\begin{array}{l}\text { Data expressed as mean } \pm S E M ; n=n u m b e r \text { of subjects; PTB ATT-naïve=pulmonary } \\
\text { tuberculosis and anti-tuberculous therapy-naïve; PTB on ATT=pulmonary } \\
\text { tuberculosis on anti-tuberculous therapy drugs; values differ significantly at }{ }^{2} p<0.01 ; \\
\text { 'p } p<0.001 \text { by Bonferroni's multiple comparison test. }\end{array}$} \\
\hline
\end{tabular}

\begin{tabular}{|c|c|c|}
\hline & \multicolumn{2}{|c|}{ OSI } \\
\hline & $r$ & p \\
\hline MDA & 0.367 & 0.020 \\
\hline NO & 0.642 & 0.000 \\
\hline TAS & -0.138 & 0.396 \\
\hline
\end{tabular}

\section{DISCUSSION}

Tuberculosis remains one of the top killers among infectious diseases. It is the most feared disease in the world and it is transmitted from person to person through aerosol from an infected air. ${ }^{12}$ Oxidative stress (OS) due to an imbalance between reactive oxygen species (ROS) and antioxidant defence mechanism in favour of the former has been implicated in the development and prognosis of PTB. ${ }^{13-14}$

The present study showed that tuberculosis is common in the study subjects between the ages of $18-28$ and $29-39$ years. Our result agreed with the report of $\mathrm{WHO}^{1}$ that tuberculosis primarily affects people during their most productive years. Similarly, higher number of tuberculosis cases were observed among males with 22 (55\%) and $32(80 \%)$ in PTB ATT-naïve and PTB patients on AT'T treatment respectively. This result was also in tandem with the previous report. ${ }^{15}$ Among the participants, the higher number of PTB cases observed among the Fulani, followed by the Hausa tribes could be attributed to the ethnicity of the inhabitants of the study environment which are predominantly Fulani and Hausa.

Low level of Western education is also another factor promoting the spread of $M$. tuberculosis infection among the study population. The highest number of PTB cases were observed among subjects with Arabic education with $14(35 \%)$ and $13(32.5 \%)$ among PTB ATT-naïve and PTB on AT'T respectively. The lowest PTB cases were demonstrated among those that attended tertiary and nonformal education with $6(15 \%)$ and $4(10 \%)$ among PTB AT'T-naive and those on AT'T respectively. These findings could be attributed to the nature of their congested rooms with no crossed ventilation which can easily transmit the M. tuberculosis infection by mere inhalation of the aerosols from an infected person. Conversely, marital status, occupation, type of family were not associated with active TB infection in the present study.

As expected the higher number of PTB patients with severe malnutrition as measured by BMI in the present study were in agreement with the studies conducted in Zimbabwe. ${ }^{16}$ and Ethiopia. ${ }^{15}$ The observed malnutrition among PTB patients at the time of participation suggest that malnutrition could play a pivotal role in the pathogenesis of active tuberculosis.

The present study also showed that oxidative stress resulting from overproduction of reactive oxygen species (ROS) and reactive nitrogen species (RNS) have been detected in PTB patients. The increased serum TOS and OSI accompanied by the reduction in serum TAS levels in PTB patients is coherent with the increased oxidative stress found in this study. This is supported by the fact that an ongoing oxidative stress triggered by the enhanced generation of reactive oxygen species by activated phagocytes overwhelmed the antioxidant capacity of the PTB patients. ${ }^{17-20}$

The response of the macrophages disrupts the balance between oxidant and antioxidant system in favour of the oxidants thereby causing oxidative damage and this may also promote tissue injury and inflammation, and further contribute to immune suppression with impaired antioxidant capacity in PTB patients. ${ }^{21}$ Cell membranes 


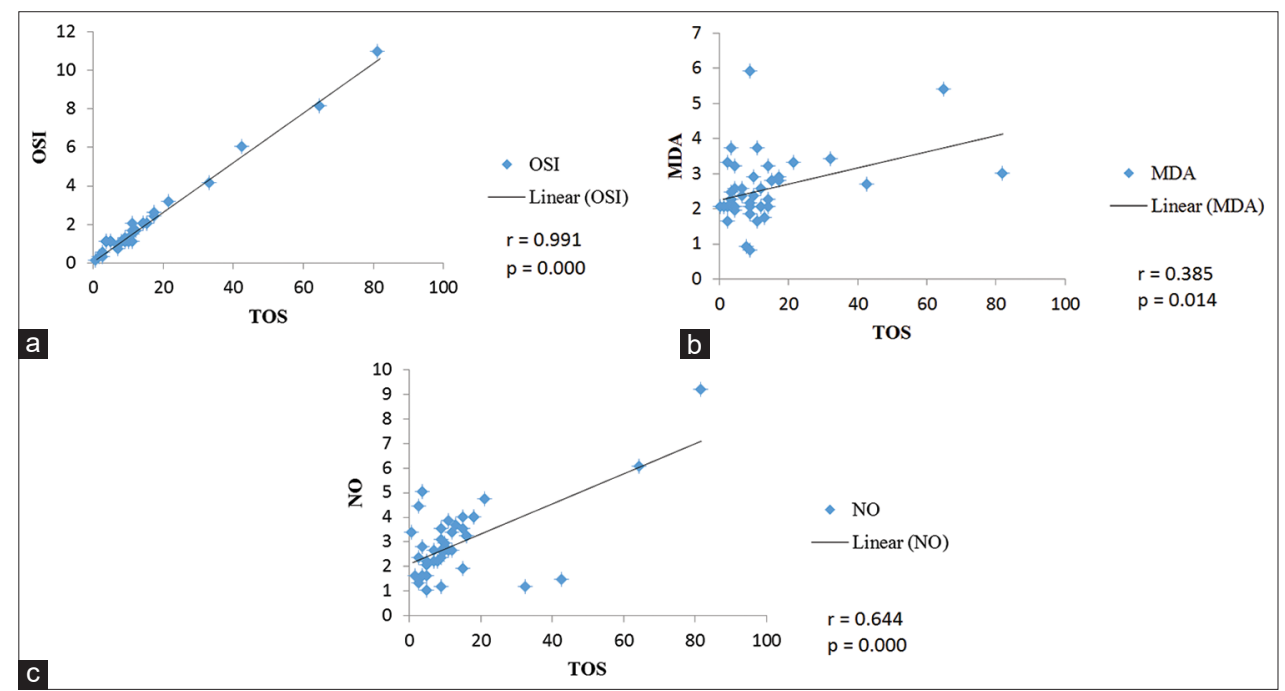

Figure 1: Dispersion graphs between serum total oxidant status (TOS) levels and a, oxidative stress index (OSI), b, malondialdehyde (MDA) and c, nitric oxide (NO) levels in anti-tuberculosis therapy naïve PTB patients.

are also attacked by free radicals resulting to tissue damage and wasting disease in PTB patients. ${ }^{22}$ Hence, our findings further contributes to the pathogenesis of active TB disease.

On the other hand, MDA levels were significantly increased in patients with PTB. These results agreed with previous literature indicating that PTB patients present with enhanced lipid peroxidation. ${ }^{17,23-24} \mathrm{~A} 2.5$ fold increment of MDA levels in PTB patients had earlier been reported. ${ }^{25}$ Nitric oxide (NO) is an important molecule that serves as a marker of oxidative stress and as a pro-oxidant molecule. In the present study, PTB subjects presented with significant elevation in NO levels. Our result corroborated with the report of previous studies. ${ }^{26-27}$

In this study, serum TOS levels were positively correlated with OSI, MDA and NO in ATT-naïve PTB patients. However, our results did not show a significant correlation between serum TAS and OSI in controls, ATT-naïve PTB and PTB patients on anti-tuberculosis therapy drugs. Significant correlations between serum TOS levels and each of serum MDA, NO and OSI suggests that an ongoing oxidative stress together with persistent immune activation due to Mycobacterial tuberculosis infectious load may be responsible in PTB patients. ${ }^{28}$

\section{CONCLUSION}

The result indicates an increased oxidative stress biomarkers accompanied by a decreased in total antioxidant status in pulmonary tuberculosis patients. The excessive generation of reactive oxygen and nitrogen species, and lipid peroxidation could be responsible. Antioxidant supplementation and improved nutrition in the management of pulmonary tuberculosis patients may go a long way in preventing the oxidative onslaught and further complications.

\section{ACKNOWLEDGMENT}

Gombe State Specialist Hospital and Department of Chemical Pathology, Usmanu Danfodiyo University, Sokoto.

\section{REFERENCES}

1. World Health Organization. Global Tuberculosis Control, Country Profiles. World Health Organization Report 2012.

2. Cheresh P, Kim SJ, Tulasiram S and Kamp DW. Oxidative stress and pulmonary fibrosis. Biochimica Biophys Acta Mol Basis Dis 2013; 1832 (7): 1028-1040.

3. Chong WC, Shastri MD and Eri R. Endoplasmic reticulum stress and oxidative stress: a vicious nexus implicated in bowel disease pathophysiology. Int J Mol Sci 2017; 18 (4): 771- 2017.

4. Gundamaraju R, Vemuri R, Chong WC, Geraghty DP and Eri R. Cell stress signaling cascades regulating cell fate. Curr Pharm Des 2018; 24 (27): 3176-3183. Doi: 10.2174/138161282466618 0711122753.

5. Agarwal A, Gupta S, Sekhon L and Shah R. Redox considerations in female reproductive function and assisted reproduction: from molecular mechanisms to health implications. Antioxid Redox Signal 2012; 10:1375-1403.

6. Elahi NJ, Saboda K, O'Connor J, Nasca PC, Stanek EJ and Boyle C. A prospective study of early pregnancy loss. Hum Reprod 2009; 11: 406-412.

7. Madhur D, Shastri I, Shakti DS, Wai CC, Kamal D, Gregory MP et al. Role of oxidative stress in the pathology and management of human tuberculosis. Oxid Med Cell Longev Vol. 2018, Article ID 7695364, 10 pages. https://doi.org/10.1155/2018/7695364.

8. Ragunath RR and Madhavi SP. Plasma oxidant antioxidant status in different respiratory disorders. Indian J Clin Biochem 2006; 21(2): 161-164.

9. Benzie IF and Strain IJ. The Ferric reducing ability of plasma (FRAP) as a measure of "antioxidant power": the FRAP assay. 
Anal Biochem 1996; 239 (1): 70-76.

10. Shah JK and Walker's AM. Quantitive determination of malondialdehydes (MDA). Biochim Biophys Acta 1989; 11:207-211.

11. Norwad R. Nitric oxide. J NIH Res 1992; 4: 49-55.

12. Smith I. Mycobacterium tuberculosis pathogenesis and molecular determinants of virulence. Clin Microbiol Rev 2003; 16 (3): 463-496. Doi: 10.1128/CMR.16.3.463-496. 2003.

13. Wiid I, Seaman T, Hoal EG, Benade AJ and Van Helden PD. Total antioxidant levels are low during active TB and rise with anti-tuberculosis therapy. IUBMB Life 2004; 56 (2):101-106.

14. Palanisamy GS, Kirk NM, Ackart DF, Shanley CA, Orme IM and Randall J. Evidence for oxidative stress and defective antioxidant response in guinea pigs with tuberculosis. PLoS One 2011; 6 (10): e2625 http://doi.org/10.1371/journal.pone.002654.

15. Gebrehiot G, Daniel S, Getnet $Y$ and Menon MKC. The non-enzymatic antioxidants and level of oxidative stress of tuberculosis patients in selected treatment centers in Addis Ababa Ethiopia. J Tuberc Res 2015; 3: 63-71.

16. Benova L, Fielding K, Greig J, Nyang'wa BT, Casas EC, da Fonseca MS et al. Association of BMl category change with TB treatment mortality in HIV-positive smear-negative and extrapulmonary TB patients in Myanmar and Zimbabwe. PLoS One 2012; 7 (4): e35948 doi: 101371/journal.pone.0035948.

17. Reddy YN, Murthy SV, Krishna DR and Probhakar MC. Role of free radicals and antioxidants in tuberculosis patients. Indian $\mathrm{J}$ Tuberc 2004; 51: 213-218.

18. Sahbettin S, Niyet C, Abdurrahman K, Ozcan E, Nurten A, Mehmet G, et al. PONi activity and total antioxidant status in patients with pulmonary tuberculosis. Clin Biochem 2007; 41(3):140-144.

19. Akiibinu MO, Arinola OG and Ogunyemi EO. Plasma neopterin and peroxide levels in pulmonary tuberculosis patients on chemotherapy without supplementation. Pak J Med Sci 2009; 25(3): 380-385.

20. Emel T, Ahmet HG, Erkan C, Tarik U, Ozlem G and Ulkan K. Serum peroxinaes 1 activity and oxidative stress in pulmonary tuberculosis. Med Princ Pract 2014; 23:426-431.

21. Wasiu OA, Ayodeji OF and Suleiman AN. Effects of treatment on free radicals in patients with pulmonary tuberculosis in SouthWestern Nigeria. Afri Health Sci 2015; 15 (4): 1256-1261.

22. Akiibinu OM, Ogunyemi OE, Arinola OG, Adenaike $A F$ and Adegoke OD. Assessment of antioxidants and nutritional status of pulmonary tuberculosis patients in Nigeria. Eur J Gen Med 2008; 5(4): 208-211.

23. Nwanjo HU and Oze GO. Oxidative imbalance and nonenzymatic antioxidant status in pulmonary tuberculosis infected subjects: Carcinogenic potential. Pak J Nutri 2007; 6 (6):590-592.

24. Mokogwu ATH, Airhomwanbor KO, Mokogwu EE and Onohwakpor EA. Lipid peroxidation and oxidative stress in pulmonary tuberculosis in Edo State, Nigeria. Afri j Cell Pathol 2016; 7: 35-40.

25. Hashmi MA, Ahsan B, Shah SIA and Khan MUI. Antioxidant capacity and lipid peroxidation product in pulmonary tuberculosis. Al Ameen J Med Sci 2012; 5 (3): 313-319.

26. Shuhangi MD, Vinayak WP, Nagsen NR, Jaisng MP and Sarita UG. Nitric oxide, carbonyl protein, lipid peroxidation and correlation between vitamins in different categories of pulmonary and extra pulmonary tuberculosis. Malays J Med Sci 2013; 20 (1): 21-30.

27. Vishal $W$, Shreewadan $R$, Sandeepan $M$, Anant $U$ and Deepak M. Assessment of oxidative stress in serum of pulmonary tuberculosis patients. Int J Res Med Sci 2016; 4 (8): 3328-3332.

28. Suresh DR, Annam $V$ and Hamsaveena PK. Immunological correlation of oxidative stress markers in tuberculosis patients. Int J Biol Med Res 2010; 1(4): 185-187.

\footnotetext{
Authors Contribution:

MHY-Concept and design of the study, statistically analyzed, interpreted data and critical revision of the manuscript; YI- Concept and design of the study, reviewed the literature and preparation of first draft of the manuscript; SAA-Critical revision of manuscript and review of the study; IMD- Helped in recruiting the patients and data collection; BS- Data gathering and assisted in statistical analysis; MD- Helped in blood samples collection and analysis; MB- Blood samples collection and processing; UY- Reviewed the literature and helped in the preparation of the first draft of manuscript.

Work attributed to:

Department of Chemical Pathology, School of Medical Laboratory Sciences, Usmanu Danfodiyo University, Sokoto.

Orcid ID:

Dr. Mohammed Haruna Yeldu - (i) https://orcid.org/0000-0002-9430-9361

Mr. Yakubu Ibrahim - (1) https://orcid.org/0000-0003-4178-7770

Dr. Isah Muhammad Danasabe - (i) https://orcid.org/0000-0002-9505-7426

Mr. Buhari Shehu - (i) https://orcid.org/0000-0001-6308-8888

Mr. Mohammed Danjuma - https://orcid.org/0000-0001-6956-3408

Mr. Miftahu Bello - (1) https://orcid.org/0000-0002-1582-8076

Mr. Usman Yahaya - (1) https://orcid.org/0000-0003-3972-5371

Source of Support: Nil, Conflict of Interest: None declared.
} 